\title{
Using subtitles for the deaf and hard of hearing as an innovative pedagogical tool in the language class
}

\author{
NOA TALAVÁN \\ Universidad Nacional de Educación a Distancia (Spain)
}

Received: 30/07/2018. Accepted: 13/03/2019.

\begin{abstract}
The present article describes a didactic proposal based on the use of an audiovisual translation and accessibility mode as a pedagogical tool: subtitles for the deaf and hard of hearing (SDH). When students create SDH for a pre-selected clip within a well-structured task, they are enhancing integrated skills, especially in the form of written production (of the subtitles), listening comprehension (of the original), and lexical creativity (through the condensation of the original message in the form of subtitles and the description of paralinguistic elements). A project undertaken with online students to assess the potential benefits of SDH has acted as a preliminary study to back up the didactic proposal presented herein. The main data gathered from this experience offers a reference for future practice and research in this field, since it confirms previous assumptions on the validity of subtitling as a pedagogical tool to improve foreign language learning skills.
\end{abstract}

KEYWORDS: Audiovisual translation, subtitles for the deaf and hard of hearing (SDH), integrated skills practice, online learning, listening comprehension, writing production.

\section{INTRODUCTION}

Research on the use of innovative pedagogical tools involving the implementation of ICTs in foreign language (L2) education has been growing non-stop in the last decades. Within this trend, the use of subtitling as a resource in L2 contexts has been attracting increasing attention (Alonso-Pérez \& Sánchez-Requena, 2018). The educational use of audiovisual

*Address for correspondence: UNED, Facultad de Filología (Desp. 523a). P. Senda del Rey, 7. 28040 Madrid; e-mail: ntalavan@flog.uned.es 
translation (AVT) modes, such as subtitling (understood in an active sense, as subtitles produced by the students themselves), profits from the combination of the benefits involved in the use of both authentic materials and technology in the language class. On the one hand, the videos to be subtitled usually come from movies, TV series or similar online video platforms, or streaming services; on the other, students need to use a specific software to interact with the video and create the subtitles. Additionally, this type of pedagogical setting is authentic on its own, since it implies a task per se, provided that learners perform the role of subtitlers and can later watch and share their final tasks as complete units. Subtitling as an active task is an activity that may easily combine individual and collaborative work, as further sections of this paper will exemplify, one that perfectly adapts to both face-to-face (F2F) and distance education/online learning environments while catering for diverse students' needs (it may equally attract visual, auditory or kinaesthetic learners), and one that allows for the creation of a realistic and familiar learning context and provides students with the opportunity to develop their ICT skills by playing to imitate a professional task.

The digitalization of audiovisual texts has radically changed the manner in which society consumes audiovisual information. It facilitates the creation, production, distribution and potential manipulation of new audiovisual contents, where the concept of prosumers (merging the figures of consumers and producers) is increasingly repeated. This process has entailed a clear empowerment of the audience accompanied by a bloom of new forms of elaboration and consumption of audiovisual products that also implies the optimization of the use of new devices (laptops, tablets, smartphones) and new communication forms, i.e. social networks. Lately, we have witnessed the consolidation of some ludic forms that were popular in the last decades, such as videogames, webtoons or webseries, or even the rise of new narratives in the form of transmedia projects. Such scenario has called for an increasingly growing demand of AVT and accessibility (as it is the case of SDH) and it is one of the main reasons behind the growing relevance of AVT as a discipline in the present world. It would not be reasonable to leave all these new and ever-present realities out of the pedagogical context.

This paper takes one AVT mode, SDH, and presents it as an innovative pedagogical tool in the L2 context. The main idea is to provide the theoretical basis for a didactic proposal based on the production of SDH on the part of students within a pre-designed lesson that may be used for L2 integrated skills enhancement. Once the theoretical basis and the proposal are explained, an experiment will be described and analysed in order to assess to what extent the AVT mode of SDH can enhance L2 skills in general and writing and listening production in particular. 


\section{THEORETICAL FRAMEWORK}

At present, AVT as a discipline on its own is of paramount relevance (Chaume, 2018). Out of the total number of translations we consume weekly, a very important number are audiovisual. Hence, AVT is a significant professional and academic field today that can be said to act as a source of knowledge, cultural information and accessibility; it seems then almost natural (and maybe also necessary) to profit from its prominence and versatility by applying it to the L2 scenario, as the present article will suggest.

AVT is a form of translation characterised by a linguistic and cultural transfer of an audiovisual text, i.e. a text whose message springs from the combination and interaction between two channels: acoustic and visual. In other words, AVT caters for the translations produced in the context of cinema, TV, videogames, theatre plays and similar audiovisual settings. The best-known AVT modes are subtitling, dubbing, voice-over, narration, and videogame localisation, together with the main audiovisual accessibility modes of audio description for the blind and SDH (Díaz Cintas \& Remael, 2012; Talaván, Ávila-Cabrera \& Costal, 2016). Any of the aforementioned AVT modes may be used in the context of L2 learning (Talaván, 2013).

The ever-growing prominence of AVT today goes hand in hand with the power of technological progress. The rapid evolution of technology has had a tremendous impact in the field of AVT in particular; in the last ten years the discipline has largely changed, both in terms of how it is produced and how it is consumed, and especially in the increasingly growing demand and consumption of audiovisual translations (Díaz-Cintas, 2018). Within this picture, it is necessary to bear in mind the present existence of a very active audience, an audience who can freely choose between dubbed or subtitled products (and/or the corresponding foreign language), produce their own audiovisual translations (creating their own fansubs or fundubs), work on transmedia extensions, manipulate ready-made audiovisual products, or even dare to send personalised feedback to distributors and authors. It is a type of audience that includes L2 students, who can also directly benefit from the didactic applications of AVT (in any of its modes) to the educational context. Using AVT as a pedagogical resource in L2 education brings real and authentic tasks to the class. These tasks do not only include audiovisual elements combined with technological elements (as beneficial as they are for learners), but they also involve the didactic use of translation in this educational context, with all the potential benefits it entails (Cook, 2010), linked to the familiarity of the multimodal and multisemiotic dimension of this particular type of task; all in all, a realistic and familiar context, where both game and professional projection come into play.

Up to now, training and research in the realm of AVT applications to L2 contexts have specially focused on the use of subtitling and dubbing as didactic tools (Incalcaterra McLoughlin, Lertola \& Talaván, 2018). Within subtitling, more emphasis has been placed on

(C) Servicio de Publicaciones. Universidad de Murcia. All rights reserved. IJES, vol. 19(1), 2019, pp. 21-40

Print ISSN: 1578-7044; Online ISSN: 1989-6131 
the pedagogical application of interlingual subtitling (students creating subtitles from L2 audio to L1 text or from L1 audio to L2 text) used as a tool to enhance listening (Talaván, 2010, 2011), writing (Talaván \& Rodríguez-Arancón, 2014a,b; Talaván, Ibáñez \& Bárcena, 2017) and vocabulary skills (Lertola, 2012), as well as intercultural and pragmatic awareness (Borguetti, 2011; Incalcaterra McLoughlin, 2009). As far as intralingual subtitling is concerned (learners working on the addition of subtitles from L2 audio to L2 text), research is still scarce and it has mainly centred on the combined development of listening and writing skills (Talaván, Lertola, \& Costal, 2016); even if the latter (L2-L2) is a less common form of translation, it seems to have a significant didactic potential, given that students need to listen repeatedly to the original so as to rephrase the oral messages (in a condensed manner) to write them on the screen in the form of subtitles.

The present proposal attempts to complement the research on intralingual subtitling moving a step further and assessing the power of an audiovisual accessibility mode that, to the author's knowledge, has not been the focus of any publication to date: intralingual SDH. A related accessible mode that has started to be researched in the field of L2 education in the past few years is audio description for the blind, where diverse benefits have been found in terms of oral production (Ibáñez, Jordano \& Vermeulen, 2015; Talaván \& Lertola, 2016), vocabulary (Ibáñez \& Vermeulen, 2013), and integrated skills enhancement (Ibáñez \& Vermeulen, 2014).

It must be noted that SDH in general, and intralingual SDH in particular, contain a series of features that distinguish them from regular subtitles (for hearing audiences), the most relevant in didactic terms being the paralinguistic information that needs to be included so that the potential audience (with hearing impairments) can have access to the sounds, tone, mood and music contained in the audio track of the video through the subtitles. The following subsection will describe in detail the expected potential benefits of the use of SDH as an innovative didactic resource in L2 learning, but it will start by analysing the role of authentic video as a didactic tool as this is the input students work with to create subtitles.

\subsection{Authentic video and SDH as pedagogical tools}

The input received when we use video as a didactic resource comes from a combination of codes (visual and textual) that allows for better recognition and retention and also makes watching video cognitively less demanding than simply listening to audio or reading a text (Sherman, 2003). Apart from receiving an input that is easier to understand and remember, as well as perceived as genuine by the recipients, there is always an emotional involvement (derived from the fact that video is what we use for recreation) that can make students feel more motivated and relaxed. 
Of course, not all videos work; video selection needs to be meticulously performed (Talaván, 2013). First, we should use short videos: 1-3 minutes is the most typically recommended duration to keep the interest of the learners (longer extracts easily lead to distraction) and to allow for the effective exploitation of all the relevant linguistic content included in the clip. Also, it is preferable to select extracts where the sound matches the image in a straightforward manner, so as to help understanding out of the visual context when new or challenging vocabulary or grammar is involved. Likewise, it will be more efficient to use self-contained videos (where the viewer does not need any background information to follow the scene), with a small number of characters, and with a linguistic level of difficulty adapted to the corresponding group of students. Furthermore, videos that engage viewers with an interesting plot and can also motivate learners through the use of humour are also ideal; it should be remembered that humour does not have to be only linguistic — something that could be too advanced for L2 learners - but it may also be visual or a combination of both.

Although the concept of authenticity and the role of authentic materials in the L2 context is still a debated notion (Buendgens-Kosten, 2014; Gilmore, 2007), within the task presented herein, the efficient role of authentic video can be clearly observed. Through authentic video as the main linguistic input, students can develop authentic listening skills, since this type of authenticity allows them to become familiar with fast speech, hesitations, overlapping, etc. In fact, audiovisual language (the language of films, TV series and the like) is said to be even more suitable for L2 learners than real authentic input (Talaván \& ÁvilaCabrera, 2015), since it takes out unnecessary hesitations and overlapping, as well as incorrect structures and lexical choices, while it keeps the essential authenticity necessary for students to become familiar with real world communication skills, that is, with real language; for the language found in authentic video is true to life and it reflects recognisable behaviour of proficient users in diverse communicative situations (Forchini, 2012), as well as positive evidence of "what is possible, acceptable and usual in the L2" (Pavesi, 2015: 91). Hence, receiving, processing and reproducing this type of language when students produce subtitles, helps them to become familiar with authentic input in a more controlled natural setting.

Given that "reality does not travel with the text" (Widdowson, 1998: 711), students need to make the text real by making it become real discourse. When learners produce subtitles for a preselected authentic video, they are working on creating discourse by interacting with a given audiovisual input. While the distinction between intentional and incidental acquisition is commonly heard in L2 learning (when students make deliberate efforts to learn a specific linguistic feature or when they simply pick up features from input they are exposed to), in an activity where the creation of subtitles is involved, both types of acquisition can be said to be at play: learners are exposed to audiovisual input, which favours 
incidental learning, while they interact with that input to make an intentional effort to create new linguistic structures to transfer the message of the audio track to the subtitles.

In particular, the creation of SDH for preselected authentic videos on the part of learners within a pre-designed L2 task implies a very complete activity where a connection between audio, images and written text takes place in the learners' minds. Additionally, they can develop interpretative listening (by listening for the gist, the message they need to transfer and condense into the subtitles), as well writing skills (working on cohesion, coherence, register, style, etc., when they write the subtitles), and lexical creativity (provided the need for a precise description of the sounds and other paralinguistic elements to cater for a potential audience with hearing loss). Consequently, it is an activity that works as a bridge between oral and writing skills, while it fosters active viewing (since students constantly interact with the video) and accessibility awareness (provided the social dimension of the task itself).

There are various possible combinations of SDH teachers may ask students to work with, the main ones being: interlingual SDH from L2 to L1, interlingual reverse SDH from L1 to L2, or intralingual (also known as bimodal) SDH from L2 to L2; the latter is the most natural form of SDH and probably the most efficient one in the L2 context because there is no interference of the L1 in the process of SDH production. Depending on the combination chosen, different L2 skills can be enhanced in various degrees, as the following didactic proposal will describe in detail.

\section{DIDACTIC PROPOSAL}

It is commonly discussed in the L2 scenario how tasks need to be meaningful, connected to the learners' lives, interactive, likely to satisfy the wants and needs of learners, and containing a clear outcome (Nunan, 2004). Using SDH as a pedagogical tool should satisfy all the previous requirements: it is meaningful because of its authenticity (the materials used and the task per se); connected to the learners' lives because of the familiarity of the audiovisual input, ICTs and AVT; interactive, given the constant interaction of students with the video by means of the corresponding subtitling software; likely to satisfy learners because of its motivational potential (as diverse related studies aforementioned have already shown); and with a clear outcome: the subtitled video, a token that can be shown to others, and even shared outside the educational context (with family and friends, through social networks, etc.). Students only learn what they want to learn when they want to learn it; they do not want to feel they are constantly being taught. They also need to feel there is meaning, connection, interaction, satisfaction and entertainment involved in the learning process.

The didactic proposal that serves as the basis for the experiment explained in the following section can be used in diverse contexts and adapted to particular teaching and 
learning needs. Figure 1 offers two general suggestions for implementation, one for F2F (60 minutes) lessons and the other for online contexts (1 month lessons).

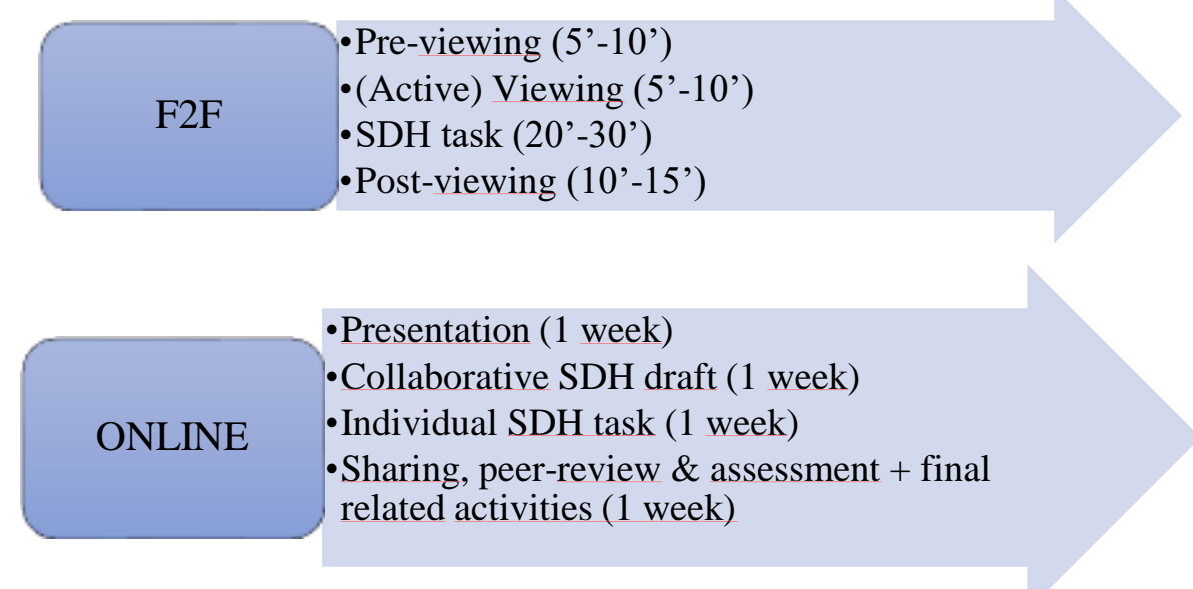

Figure 1. Lesson plan samples including the use of SDH as a didactic tool.

In both scenarios we would have a pre-viewing or presentation section where the contents of the video would be discussed and/or the new vocabulary, grammar structures, intercultural elements or communicative functions included might be put forward through diverse sorts of activities. In online environments, this presentation also includes watching the videos. The viewing stage of F2F lessons prepares students for the subsequent task of subtitling, by showing them the input; in this stage teachers may decide on the number of times the video is watched (twice at least) and the activities ${ }^{1}$ and support $^{2}$ that may accompany the viewing. Then, the core of the lesson includes the SDH task itself; in online contexts, a collaborative translation draft would be recommended first (to profit from peersupport and to facilitate the subsequent SDH task) to then individually create the subtitles using the corresponding subtitling editor. In F2F lessons, on the other hand, time restrictions only allow either individual or collaborative (typically in pairs) subtitling performed directly (with no previous written draft) using the preselected software. Finally, in a post-viewing phase, students may share their work, peer-review or self-assess it (with the help of ad-hoc rubrics prepared by teachers) and/or perform final related activities in the form of discussions, role-plays, writing tasks, etc., related with the contents and the linguistic elements included in the corresponding video (or videos, as it can be often the case in online settings).

In order to understand which L2 skills may be the focus of lessons based on the use of $\mathrm{SDH}$ as a pedagogical tool, similar to the ones described in Figure 1, here follows a description of the degree to which each communicative activity or skill may be influenced by the didactic use of SDH: 
- There will always be vocabulary enhancement due to the effort made by learners to listen to new lexical items, and either repeat them in the subtitles in written form, paraphrase them (through synonyms or equivalent structures), or recreate them (by searching for new vocabulary), depending on the degree of reduction or condensation of the original message required to fit the subtitles. Plus, new lexical items will be searched so as to name the paralinguistic information required in SDH to describe sounds, tone, mood, music, etc. with enough precision.

- Writing production skills will also be enhanced at all times during this task. Register, style selection, sequencing of ideas, correct use of coherence and cohesion (guiding the reader through the message), correct spelling, etc. will be at work during the creation of SDH.

- Oral comprehension skills are also clearly developed in this context since listening is everpresent in the task; in fact, students need to go through different stages in the comprehension process necessary to produce the subtitles: (1) interpretative listening first, looking for the gist (the main ideas or messages); (2) selective listening next, when specific words or phrases need to be reinterpreted or recreated (due to condensation and reduction needs of subtitling); finally, (3) intensive listening is at stake when students revise their final work, checking whether every single relevant detail of the audio track is matched in the subtitles.

- Other skills can also be part of the picture: (1) oral production, in a pre-task or post-task stage through discussions or role-plays that include linguistic forms and functions contained in the clip; (2) reading comprehension, if the clip is watched first with subtitles in the viewing stage or if the script is provided (in the case of lower levels of proficiency students, for example), since information scanning, interpretation from the context, learning to get the gist, acquiring a better comprehension of coherence and cohesion, etc. would be at work; finally, (3) grammar and (4) intercultural awareness can also be enhanced using SDH as a didactic tool: the former through the same 'listen, repeat, paraphrase, recreate' formula commented above for vocabulary development, and the latter depending on the clip chosen, the degree of cultural information contained therein, and the specific focus given to the corresponding lesson.

Teachers may choose to concentrate on a specific skill through ad-hoc activities or simply let students develop all of them in an integrated manner, without specially pointing to one in particular. The richness of the present proposal of the didactic use of SDH lies precisely in how complete, thorough and flexible the use of normal subtitling (for hearing audiences) as a tool has proved to be in terms of: the endless resource bank in the form of videos that is available today; how visual literacy can be constantly enhanced during the task provided the audiovisual input; the various linguistic combinations available to create the subtitles; the degree of adaptability of the lesson format to diverse L2 group types; and the possibility to work on all L2 communicative skills at once within a really active, authentic and interactive audiovisual and ICT task (Incalcaterra McLoughlin, Lertola \& Talaván, 
2018). Plus, with SDH there is extra text to be produced by the learner (the description of the corresponding paralinguistic elements), and the accessibility dimension added to this picture.

\section{A PRELIMINARY STUDY}

The study undertaken to validate the didactic proposal described above was called SubLITE (Subtitles for the deaf and hard of hearing to improve LIstening and wriTing skills in foreign language Education). It was a teaching innovation experience where a series of researchers from different institutions gathered to collaborate in a small-scale project specifically aimed at assessing SDH creation as a didactic resource in L2 online contexts. Its main focus as far as skills development is concerned was on assessing the degree of writing production and listening comprehension enhancement involved in lessons including SDH as a didactic resource.

To this end, in the course of two months, a small group of online undergraduate students of English Studies at the Universidad Nacional de Educación a Distancia (UNED), taking an English as a foreign language first year compulsory subject (Inglés Instrumental II), worked on the creation of intralingual SDH for 6 pre-selected short videos that contained a relevant set of paralinguistic features (to allow for sound, tone, mood, music, etc. description).

As far as the research sample is concerned, the subjects who completed the project were a total of 11 learners studying at the UNED. They were all Spanish native speakers, $80 \%$ female, and their average age was 36. Their proficiency level of English was B2, and most of them (70\%) felt confident about their writing and listening skills (especially the former). The majority (85\%) stated being familiar with the use of subtitles and audiovisual materials to improve L2 skills, but did not know much about SDH, and their expectations regarding the project pointed towards the improvement of listening and writing skills particularly. It should be noted that although this group of students were intermediate L2 learners, beginners and more advanced students could also profit from this activity (the former with the necessary adaptations), as it has already been the case in related previous studies (Talaván, 2010; Talaván \& Rodríguez-Arancón, 2014a,b)

The resources included in SubLITE were: 6 videos (plus a sample one used for a video tutorial), 3 video tutorials, and general instructions included in the virtual community created for the project. The videos were selected following a series of criteria: they were 1-2 minutes long, contained a small number of characters speaking, included sounds and other relevant paralinguistic features, were self-contained, and had a slight dose of humour. All but one were extracted from cartoons: the first one was a very easy and short clip from The Simpsons (Brooks, Groening \& Simon, 1989-) to help students get started, the two following ones (plus the sample video) were taken from Hercules (Clements \& Musker, 1997), the next two were extracted from Frozen (Buck \& Lee, 2013), and a final more complicated one was selected 
from the musical film Sweeney Todd: The Demon Barber of Fleet Street (Burton, 2007). They were organised so that the easier ones came first, and students would face more complicated audiovisual language, sounds and linguistic input further on in the course of the lesson.

Three video tutorials were produced ad-hoc to help students involved in SubLITE: an initial one on how to subtitle and create SDH was recorded to provide a theoretical basis for the students' practice during the subtitling activities; also, there were two more technical video tutorials created to teach learners how to work with two particular subtitling editors: AEGISUB and Clipflair. In this sense, learners were given a choice so that they could be free to decide which software was more efficient and user-friendly and worked better for them. Both editors had been used in previous similar didactic experiences and had proven to be equally valid; however, while the first one is still available as an open source tool (http://www.aegisub.org), the latter (www.clipflair.net) is ready to use but no support or updates are available anymore, as the European project that was in charge of implementing and maintaining it is over now.

Finally, the instructions prepared to guide the students through the online lesson in the virtual course were meant to organise the timing of the various tasks and to explain every phase in detail beforehand in order to foster motivation and interest, and so as to avoid misunderstandings or confusion at any point of the two-month period devoted to the project/lesson. Table 1 provides a summary of the procedures that were thoroughly explained to students in the instructions, and monitored through the forums, presenting an adaptation of the didactic proposal contained in Figure 1 (specially in terms of the duration of the central task).

\begin{tabular}{ll}
\hline \multicolumn{1}{c}{ Stage } & \multicolumn{1}{c}{ Task } \\
\hline $\begin{array}{l}\text { Preparation } \\
(1 \text { week })\end{array}$ & $\begin{array}{l}\text { Introduction to the project, completion of pre-tests and initial questionnaire, } \\
\text { watching the videos and the tutorials }\end{array}$ \\
\hline $\begin{array}{l}\text { Central task (SDH) } \\
(1 \text { month and a half })\end{array}$ & $\begin{array}{l}\text { Creating SDH for 6 videos individually, following the order provided by the } \\
\text { teachers (1 per week), and sharing each task once finished in the forums for } \\
\text { peer-review and assessment }\end{array}$ \\
\hline $\begin{array}{l}\text { Post-task } \\
(1 \text { week })\end{array}$ & $\begin{array}{l}\text { Collaborative discussion on the final outcomes of each student's SDH } \\
\text { productions, the progress followed, and the proficiency acquired, both in the } \\
\text { forums and through a final videoconference. Completion of post-tests and } \\
\text { final questionnaire }\end{array}$ \\
\hline
\end{tabular}

Table 1. Lesson plan procedures.

This is a clear example of how easily the general lesson plan sample presented in Figure 1 above can be adapted to a particular educational context. Here, individual and collaborative work were combined although there were obviously more hours devoted to individual work for the creation of the subtitles for each of the 6 videos contained in the lesson. However, peer-to-peer discussion and review was fostered by teachers in the forums 
at all times so that learners could both help each other collaboratively and reflect upon the quality of their own work by assessing their classmates' productions.

\subsection{Methodology}

The research study undertaken to gather information so as to assess the potential benefits of $\mathrm{SDH}$ as a didactic tool to improve listening and writing skills followed a triangulated design: it included language assessment tests (both writing production and listening comprehension), questionnaires, and observation as the basic data gathering tools to make the results as reliable as possible, despite the small number of subjects involved. In the study, the two main dependent variables were listening comprehension and writing production enhancement whereas the independent variable was the use of SDH as a didactic resource.

The language assessment tests (to evaluate the level of departure in terms of listening and writing skills before using SDH as a task) were designed ad-hoc bearing in mind the type of lesson and the specific group of students. The listening tests (pre and post) contained audiovisual input and two sections of closed questions (including both true/false and multiple-choice typologies); they were designed by the researchers online (the input being videos created ad-hoc) and triangulated and revised by three observers before they were passed to students. The data in this case were gathered quantitatively since each test had a total of 12 items (so marks ranged from 0 to 12). The writing tests (pre and post), on the other hand, included detailed written instructions to guide students through the tasks, as Table 2 shows. They were also previously revised and piloted by three observers before they were passed to students.

\section{WRITING PRE-TEST}

Please read the instructions carefully and follow the steps appropriately:

1. Read Charles Perrault's adaptation of the well-known popular folk tale "Little Red RidingHood" on pages 2-4 of this same document. 2. Revise the terms you have found difficult to understand and use a monolingual English dictionary to clarify their meaning.

3. Consider the similarities and differences between Perrault's tale and the Spanish adaptation you were told as a child. Make a list.

4. Write a short essay (200 words max.) in which you discuss what the moral of Perrault's story is trying to teach his intended audience of young readers, and express your opinion on how effective this message would be for a child of the early 21 st century.

5. Double-check your work in search of mistakes. Make the necessary corrections.

\section{WRITING POST-TEST}

Please read the instructions carefully and follow the steps appropriately:

1. Read Thomas Bulfinch's analysis of the Greek myths behind Hercules the demigod on pages 2-6 of this document.

2. Revise the terms you have found difficult to understand and use a monolingual English dictionary to clarify their meaning.

3. Draw comparisons between this reading and your previous knowledge of Hercules taking into account the literary and audiovisual sources from which it derived (i.e. Greek literature, Hollywood films, Disney adaptations, etc.). Make a list.

4. Write a short essay (200 words max.) in which you discuss the way myths are transformed from generation to generation. You may reflect on the case of Hercules and add your impressions about other tales which are closer to your own culture or region.

5 . Double-check your work in search of mistakes. Make the necessary corrections.

Table 2. Writing tests instructions. 
The questionnaires were created to provide a description of the sample (prequestionnaire) and to complement the data gathered from the language assessment tests and the observation of the researchers (post-questionnaire). They were carefully designed following educational research guidelines (Cohen, Manion \& Morrison, 2017) and piloted by five external observers before administration.

Finally, observation was followed by two researchers who monitored the activity in the forums and the email messages received, as well as by three researchers who carried out the assessment of the final SDH work of students following an ad-hoc rubric that included key aspects to be considered when creating SDH (Table 3).

\begin{tabular}{|l|l|}
\hline \multicolumn{2}{|c|}{ Task assessment (0-5 per item, from no evidence to excellent) } \\
\hline - General linguistic accuracy & \\
\hline - Description of sounds - accuracy & \\
\hline - Description of sounds - coverage & \\
\hline - Condensation & \multicolumn{2}{|c|}{ Description of items assessed } \\
\hline - Segmentation & Synchrony \\
\hline \multicolumn{2}{|l|}{ Total points (out of 30) } \\
\hline - & $\begin{array}{l}\text { General linguistic accuracy: the subtitles are grammatically correct (spelling, punctuation, } \\
\text { grammar, syntax). }\end{array}$ \\
\hline - & $\begin{array}{l}\text { Description of sounds - accuracy: acoustic nonverbal information is conveyed in the subtitles in } \\
\text { a grammatically correct way. }\end{array}$ \\
\hline - & $\begin{array}{l}\text { Description of sounds - coverage: correct choice of acoustic nonverbal information is included } \\
\text { in the subtitles. }\end{array}$ \\
\hline - & $\begin{array}{l}\text { Condensation: subtitles allow the audience to have enough time to read them without missing } \\
\text { visual information (i.e. avoiding too much text in the subtitle). }\end{array}$ \\
\hline - & $\begin{array}{l}\text { Segmentation: the text in the subtitle is correctly segmented (e.g. there is no break between a } \\
\text { determiner and the noun it accompanies in two subtitles nor in two lines). }\end{array}$ \\
\hline - & $\begin{array}{l}\text { Synchrony: there is synchrony between the duration of each subtitle and the duration of the } \\
\text { original actor's corresponding utterances. }\end{array}$ \\
\hline
\end{tabular}

Table 3. SDH assessment rubric for SubLITE.

\subsection{Data analysis and discussion}

The results gathered from the assessment of the tests were obtained in two different ways: the answers for the listening tests were automatically gathered (as they had been designed as multiple-choice), while the writing assignments were marked by two researchers using an adhoc rubric, and the mean of the two marks obtained per subject per test was the final mark considered in the analysis (it should be noted that on most occasions both markers agreed 
more or less on their marks). The general results summarised in Table 4 can shed some light on the potential benefits of SDH to improve listening and writing skills in higher education online contexts.

\begin{tabular}{lllll}
\hline & $\begin{array}{l}\text { LISTENING } \\
\text { pre-test }\end{array}$ & $\begin{array}{l}\text { LISTENING } \\
\text { post-test }\end{array}$ & $\begin{array}{l}\text { WRITING } \\
\text { pre-test }\end{array}$ & $\begin{array}{l}\text { WRITING } \\
\text { post-test }\end{array}$ \\
\hline MARKS & $9.63 / 12$ & $10.09 / 12$ & $5.94 / 10$ & $8.08 / 10$ \\
\hline $\begin{array}{l}\text { Standard } \\
\text { deviation }\end{array}$ & 1.28 & 1.37 & 1.84 & 1.38 \\
\hline
\end{tabular}

Table 4. Communicative skills improvement.

The previous data show certain improvement in both skills in the course of two months, more so in terms of writing. This is probably due to the fact that the writing process involved in the creation of SDH is very thorough and goes hand in hand with the development of vocabulary and grammar proficiency, all of which influences the writing progress. It should also be noted here that these results may be also influenced by the fact that there was an appreciation of a higher proficiency in this skill in particular on the part of the subjects when they completed the initial questionnaire, something that was commented in the previous description of the research sample.

Even though any normality assumption could be considered risky, in order to provide a greater degree of reliability to the previous data, a paired sample t-test was performed comparing the differences between the two tests (pre and post) in each case (Table 5).

\begin{tabular}{lll}
\hline MEASUREMENT & LISTENING & WRITING \\
\hline Mean difference & 0.45 & 2.13 \\
\hline Standard deviation & 1.96 & 1.55 \\
\hline T & 0.7 & 4.55 \\
\hline p-value & 0.23 & 0.0005 \\
\hline
\end{tabular}

Table 5. Paired sample t-test of the language assessment tests results.

Hence, even if the sample size is small, the performance of the previous statistical analysis shows a strong evidence of improvement in writing, which confirms and complements the data included in Table 4, while only a fair evidence of improvement in listening can be asserted; there are two possible reasons behind this lower effect: the small size of the sample and the fact that the initial mark in listening was rather high in itself so there was less room for potential advancement.

The previous data are complemented with the answers gathered from the final questionnaire, where students stated their appreciation in terms of L2 skills improvement thanks to the project. In this sense, Figure 2 confirms the enhancement of the writing and listening skills, but in this case the opposite tendency is observed: students perceive they developed their oral comprehension a little further than their writing production skills. 


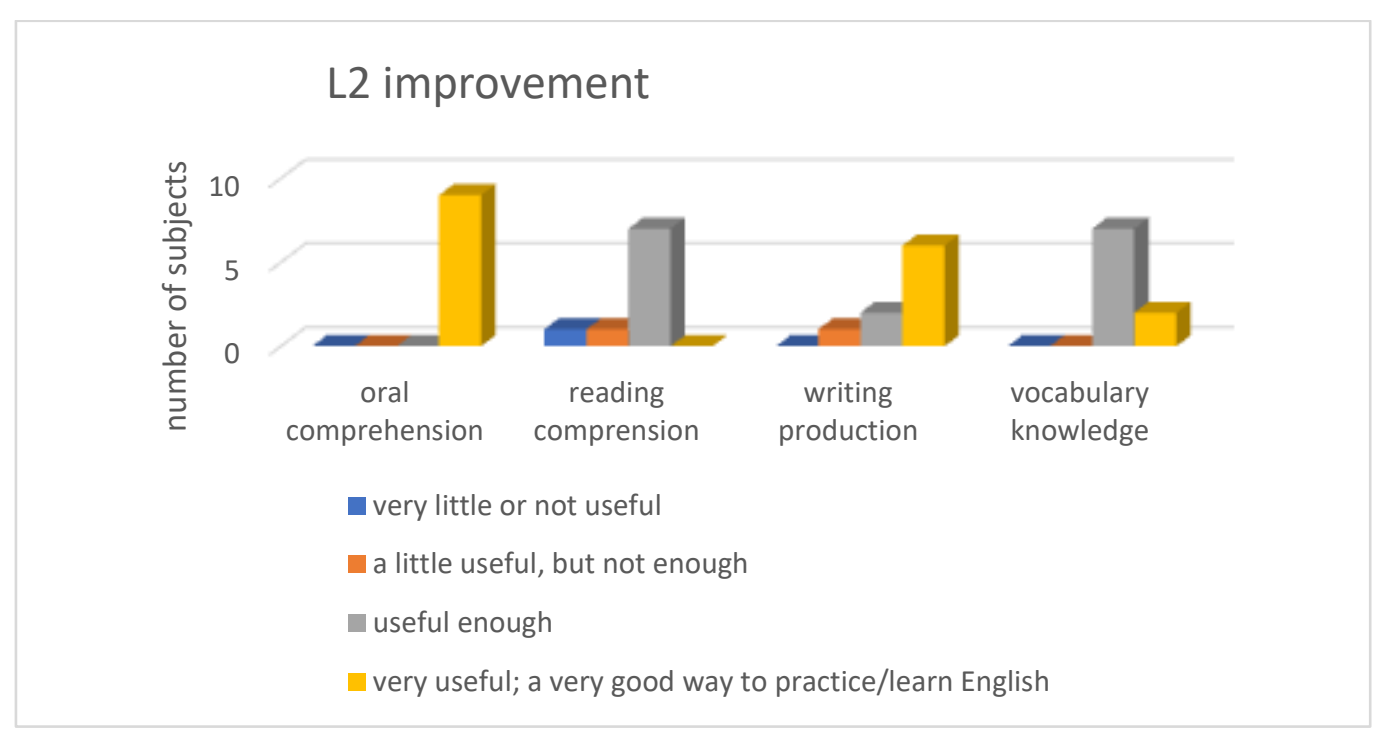

Figure 2. Learners' appreciation of L2 skills improvement.

Probably, the number of times students had to listen to every message contained in each of the 6 clips made them perceive their listening skills as the most obvious target of their L2 learning process during the project. Additionally, their answers also pointed towards the impact (although lower) of SDH on other related areas, such as vocabulary knowledge and reading comprehension (the latter was less obvious as it was not included as an intrinsic part of the task).

Other L2 benefits were considered in the post-questionnaire, such as the development of creative skills, the capacity to reflect upon their own learning process, or the enhancement of ICT skills, as can be observed in Figure 3.

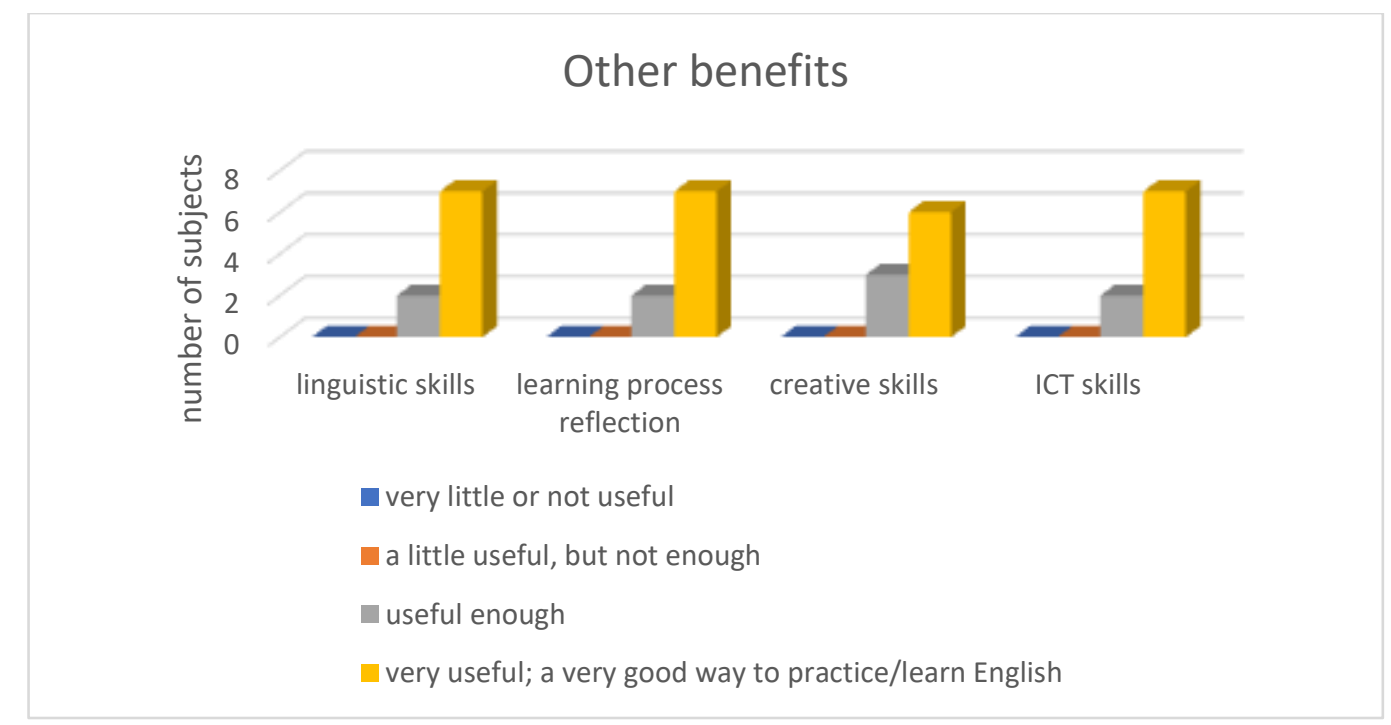

Figure 3. Other didactic advantages of the use of SDH in the L2 context. 
Hence, thanks to the use of SDH as a didactic tool, students seemed to be able to develop their L2 linguistic skills as a whole, as well as enhance their ICT skills (through the use of a specific subtitling software), while working on their creative skills (looking for new linguistic forms), and learning to reflect upon their own L2 learning process (through their progress from one video to the next and the peer-review stage). Hence, despite its inherent difficulty, as seen in Figure 4, learners highly valued the potential benefits of the task -it should be noted that all participants stated that the video tutorials had been crucial to help them undertake the SDH tasks.

\section{Task challenge}

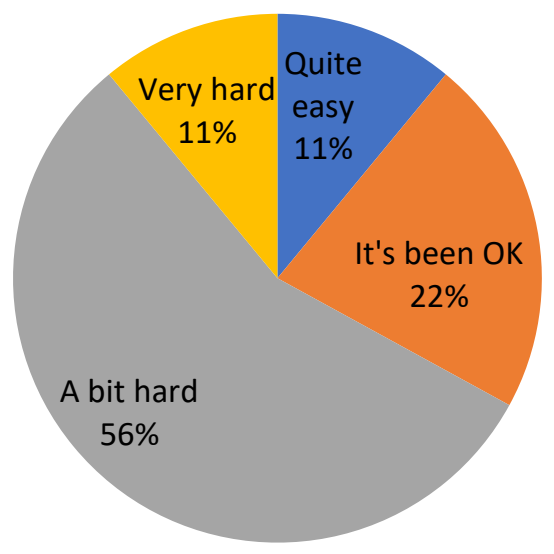

Figure 4. Degree of difficulty involved in the task of SDH in the course of the project.

This difficulty was expected given that it was the first time that these students faced this type of task. However, despite the challenge, when assessing their final work, the teachers/researchers could observe a clear improvement in the quality of the students' SDH production between videos 2 and 5 (it should be remembered that video 1 was introductory and especially easy and short - and the final clip was offered as an extra optional challenge). The average marks (ranging from 0 to 30) obtained by the different students for each of the videos (Figure 5) portray a tendency for improvement from one video to the next (particularly considering the progression between videos 2 and 5), even though each video tended to slightly increase its linguistic and paralinguistic difficulty for the creation of SDH: (1) The Simpsons (easy and short), (2) Hercules 1 (it included more sound effects and characters), (3) Hercules 2 (it was linguistically more complex), (4) Frozen 1 (it offered similar sound and linguistic complexity to video 3), (5) Frozen 2 (it contained more sounds 
but a rather similar linguistic weight), and (6) Sweeney Todd (it was not a cartoon and it was the most linguistically and visually complex clip).

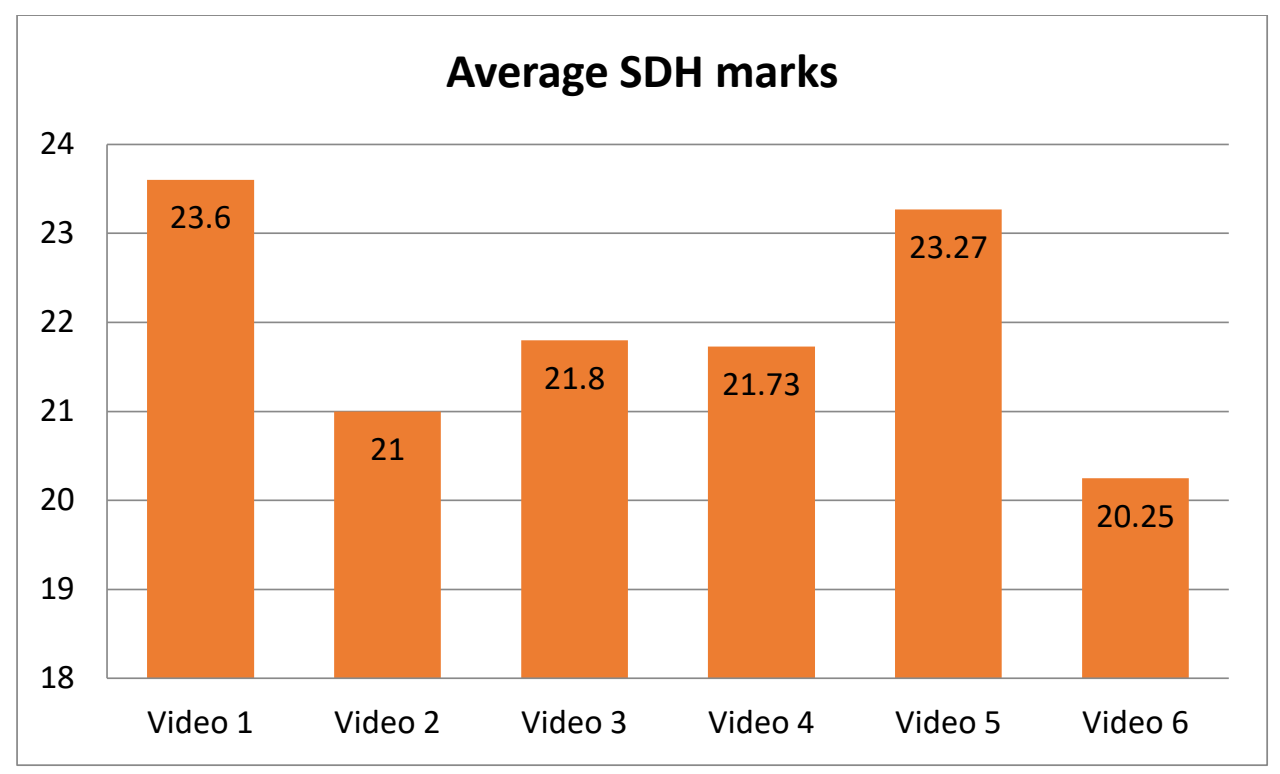

Figure 5. Learners' SDH quality progress.

The previous graph includes all six videos even if video 1 and video 6 were not supposed to be part of this analysis (as mentioned above, video 1 was introductory and video 6 was optional). ${ }^{3}$ While the simplicity of video 1 can be noticed, the extra difficulty of video 6 seems to mark an excessive difference with the previous videos; this was so especially because it was not a cartoon but a musical film, and the language was faster and more complex. However, the positive progress in SDH production quality from videos 2 to 5 can be perceived. It should be remembered that the subtitling took place in the course of one month only; so even if the progress is not extremely noticeable, there is clear advancement that can account both for the students' general progress in the creation of SDH as such, as well as for the development of their L2 proficiency in general.

An observation that may counterbalance the limitation of this study derived from such a small sample size is the intense interaction and frenetic activity of the forums, where more than 400 posts written by 11 students (and the teachers) can be tracked in the course of two months only. This perception is accompanied by the motivation observed not only in the learners' interventions in the forums and in the final videoconference, but also in the final questionnaire, where the totality of the participants asserted to be willing to repeat the experience and included observations (verbatim) such as: "Thanks very much for this project, it has been the most beautiful extra activity in the four years studying this degree", "I think it would be a good idea to create a subject only dedicated to subtitling and focused to the professional life", or "Very addictive activity; I am far from reaching perfection but the SDH subtitling but not only has it been a very entertaining, funny and motivating way of learning English but also a way of realizing other realities." 
The results obtained herein confirm and complement other studies on normal subtitling (for hearing audiences) mentioned previously in this article, such as Talaván and RodríguezArancón (2014a,b) and Talaván, Ibáñez and Bárcena (2017), where interlingual reverse subtitling was used to develop writing production and general translation skills. Furthermore, Talaván, Lertola and Costal (2016), who dealt with intralingual subtitling to enhance writing and listening skills, provided relatively similar results that could be used as a basis for data confirmation and discussion. It should be remembered, though, that SDH differs from normal (interlingual) subtitling (for hearing audiences) by adding the extra challenge included in the paralinguistic descriptions; furthermore, intralingual subtitling, as the one performed in this study, does not involve the use of the L1, and so it could be too challenging for student groups with lower proficiency levels. Consequently, for future lesson plans, it could probably be more reasonable to start with interlingual subtitling first, when introducing the activity to students, so as to try to counterbalance the challenge of learning the task of subtitling without the presence of the $\mathrm{L} 1$ in the activity.

\section{CONCLUSION}

The last EF English Proficiency Index 2017 (https://www.ef.com.es/epi/) points out that Spain, France and Italy occupy the $21^{\text {st }}, 22^{\text {nd }}$ and $23^{\text {rd }}$ positions out of 27 European countries. ${ }^{4}$ Spain, France and Italy are traditionally dubbing countries, and although the low proficiency L2 levels are not a direct consequence of this fact, subtitling used as an innovative pedagogical tool in countries like Spain may easily entail a generalisation of the relevance of watching audiovisual materials subtitled whenever possible on the part of the learners. Thus, they may easily gain in L2 proficiency provided a greater exposure to L2 in their everyday lives. In the case of SDH in particular, its use as a didactic tool also implies a deeper audiovisual accessibility awareness, as relevant as this is in our present society.

The conclusions of SubLITE project confirm the expected benefits as far as the enhancement of writing and listening skills is concerned and provide additional relevant information for further study. The use of SDH as an active task has proved to create a context where students really move beyond words and can understand the reality of communication as a whole. A real task-based learning scenario that implies a motivating, familiar, interactive and gratifying central task, that is also socially relevant and linguistically and technically challenging.

However, the study included in the present paper has just attempted to be a preliminary trial of the didactic and methodological proposal described herein. The small size of the sample and the short-term experience have turned it into a mere pilot study that calls for further replication with a larger number of subjects, varying choices of video selection, within a longer-term experience, comparing results with $\mathrm{F} 2 \mathrm{~F}$ scenarios, assessing other proficiency levels, etc. 
Therefore, this paper has provided a basis for the use of SDH as a pedagogical resource in L2 settings, by describing its theoretical basis, providing a didactic proposal and analysing the results of a preliminary research study designed to assess the validity and efficiency of this innovative tool, especially in terms of listening and writing skills enhancement. Although there is already significant research evidence as regards the didactic potential of subtitling as a didactic tool, this research could be regarded as the first one to directly deal with the creation of SDH within a pre-designed L2 lesson. Further scholarly interest would be required to maximise its pedagogical use and provide the area with a more solid basis in academia.

\section{NOTES}

1 It is advisable to perform viewing activities in the form of multiple-choice questions about the contents, fill-in-the-blanks exercises, a summary of the main ideas, or simply asking for notetaking leading to subsequent discussion, so that the viewing process may be active enough.

2 For example, if the video is watched with subtitles, extra support is provided to facilitate the subsequent task of SDH and viewing becomes less passive.

3 However, since all students completed them, it was considered pertinent to include the data gathered in this regard here as well.

4 Even if this ranking assesses primary and secondary education only, the results could be somehow generalised to other groups of L2 learners.

\section{REFERENCES}

Alonso-Pérez, R. \& Sánchez-Requena, A. (2018). Teaching Foreign Languages through Audiovisual Translation Resources. Applied Language Learning, 28(2), 1-24.

Borguetti, C. (2011). Intercultural learning through subtitling: The cultural studies approach. In L. Incalcaterra McLoughlin, M. Biscio \& M. À. Ní Mhainnín (Eds.), Audiovisual Translation Subtitles and Subtitling. Theory and Practice (pp. 111-137). Bern: Peter Lang.

Buendgens-Kosten, J. (2014). Key concepts in ELT: Authenticity. ELT Journal, 68(4), 457-459. doi: $10.1093 / \mathrm{elt} / \mathrm{ccu} 034$

Chaume, F. (2018). Is audiovisual translation putting the concept of translation up against the ropes?

The Journal of Specialised Translation, 30. Retrieved July 10, 2018 from https://www.jostrans.org/issue30/art_chaume.php

Cohen, L., Manion, L. \& Morrison, K. (2017). Research Methods in Education. London: Routledge.

Cook, G. (2010). Translation in language teaching. Oxford: Oxford University Press.

Díaz-Cintas, J. (2018). 'Subtitling's a carnival': New practices in cyberspace. The Journal of Specialised Translation, 30. Retrieved July 23, 2018 from https://www.jostrans.org/issue30/art_diaz-cintas.php

Díaz Cintas, J. \& Remael, A. (2012). Audiovisual Translation: Subtitling. Oxon: Routledge. 
Forchini, P. (2012). Movie language revisited. Evidence from multi-dimensional Analysis and Corpora. Bern: Peter Lang.

Gilmore, A. (2007). Authentic materials and authenticity in foreign language learning. Language Teaching, 40, 97-118. doi: 10.1017/S0261444807004144

Ibáñez, A., Jordano, M. \& Vermeulen, A. (2015). VISP design and evaluation, a mobile application to practice oral competence. Revista Iberoamericana de Educación a Distancia, 19(1), 63-81.

Ibáñez, A. \& Vermeulen, A. (2013). Audio Description as a Tool to Improve Lexical and Phraseological Competence in Foreign Language Learning. In D. Tsagari \& G. Floros (Eds.), Translation in language Teaching and Assessment (pp. 41-65). Newcastle upon Tyne: Cambridge Scholars Publishing.

Ibáñez, A. \& Vermeulen, A. (2014). La audiodescripción como técnica aplicada a la enseñanza y aprendizaje de lenguas para promover el desarrollo integrado de competencias. In R. Orozco (Ed.), New Directions in Hispanic Linguistics (pp. 16-34). Newcastle upon Tyne: Cambridge Scholars Publishing.

Incalcaterra McLoughlin, L. (2009). Inter-semiotic translation in foreign language acquisition: The case of subtitles. In A. Witte, T. Harden \& A. Ramos de Oliveira (Eds.), Translation in Second Language Learning and Teaching (pp. 227-244). Bern: Peter Lang.

Incalcaterra McLoughlin, L., Lertola, J. \& Talaván, N. (2018). Editorial. In L. Incalcaterra McLoughlin, J. Lertola \& N. Talaván (Eds.), Translation and Translanguaging in Multilingual Contexts. Special Issue Audiovisual translation in applied linguistics: Educational perspectives (pp. 1-8). Amsterdam: John Benjamins. doi: 10.1075/ttmc.00001.edi

Lertola, J. (2012). The effect of the subtitling task on vocabulary learning. In A. Pym \& D. OrregoCarmona (Eds.), Translation research projects 4 (pp. 61-70). Tarragona: Universitat Rovira i Virgili.

Nunan, D. (2004). Task-Based Language Teaching. Cambridge: Cambridge University Press.

Pavesi, M. (2015). From the screen to the viewer-learner. Audiovisual input as a context for second language acquisition. In S. Campagna, E. Ochse, V. Pulchini \& M. Solly (Eds.), Languaging In and Across Communities: New Voices, New Identities. Studies in Honour of Giuseppina Cortese (pp. 83-104). Bern: Peter Lang.

Sherman, J. (2003). Using authentic video in the language classroom. Cambridge: Cambridge University Press. doi: 10.1093/elt/cci014

Talaván, N. (2010). Subtitling as a Task and Subtitles as Support: Pedagogical Applications. In J. Díaz-Cintas, A. Matamala \& J. Neves (Eds.), New Insights into Audiovisual Translation and Media Accessibility (pp. 285-299). New York, NY: Rodopi.

Talaván, N. (2011). A Quasi-Experimental Research Project on Subtitling and Foreign Language Acquisition. In L. Incalcaterra McLoughlin, M. Biscio \& M. Á. Ní Mhainnín (Eds.), Subtitles and Subtitling. Theory and Practice (pp. 197-218). Bern: Peter Lang.

Talaván, N. (2013). La subtitulación en el aprendizaje de lenguas extranjeras. Barcelona: Octaedro.

Talaván, N. \& Ávila-Cabrera, J. J. (2015). Audiovisual reception and mall: Adapting technology to real needs. Porta Linguarum, 24, 33-46. Retrieved July 15, 2018 from http://www.ugr.es/ portalin/articulos/PL_numero24/3NOA.pdf

Talaván, N., Ávila-Cabrera, J. \& Costal, T. (2016). Traducción y accesibilidad audiovisual. Barcelona: Editorial UOC.

(C) Servicio de Publicaciones. Universidad de Murcia. All rights reserved. IJES, vol. 19(1), 2019, pp. 21-40 Print ISSN: 1578-7044; Online ISSN: 1989-6131 
Talaván, N., Ibáñez, A. \& Bárcena, E. (2017). Exploring collaborative reverse subtitling for the enhancement of written production activities in English as a second language. ReCALL, 29(1), 39-58. doi: 10.1017/S0958344016000197

Talaván, N. \& Lertola, J. (2016). Active audiodescription to promote speaking skills in online environments. Sintagma, Revista de Lingüística, 28, 59-74. doi: 10.21001/sintagma.2016.28.04

Talaván, N., Lertola, J. \& Costal, T. (2016). iCap: Intralingual Captioning for Writing and Vocabulary Enhancement. Alicante Journal of English Studies, 29, 229-247.

Talaván, N. \& Rodríguez-Arancón, P. (2014a). The use of interlingual subtitling to improve listening comprehension skills in advanced EFL students. In B. Garzelli \& M. Baldo (Eds.), Subtitling and Intercultural Communication. European Languages and beyond (pp. 273-288). Pisa: InterLinguistica ETS.

Talaván, N. \& Rodríguez-Arancón, P. (2014b). The use of reverse subtitling as an online collaborative language learning tool. Interpreter and Translator Trainer, 8(1), 84-101. doi: 10.1080/1750399X.2014.908559

Widdowson, H. G. (1998). Context, Community, and Authentic Language. TESOL Quarterly, 32(4), 705-736. doi: $10.2307 / 3588001$ 